\title{
Comparison of Blood Transfusion Plus Chelation Therapy and Bone Marrow Transplantation in Patients with $\beta$-Thalassemia: Application of SF-36, EQ-5D, and Visual Analogue Scale Measures
}

\author{
Mehdi Javanbakht ${ }^{1}$, Ali Keshtkaran ${ }^{2}$, Hossien Shabaninejad ${ }^{3,4}$, Hassan Karami ${ }^{*}$, Maryam Zakerinia ${ }^{5}$, Sajad Delavari ${ }^{6}$
}

\begin{abstract}
Background: $\beta$-Thalassemia is a prevalent genetic disease in Mediterranean countries. The most common treatments for this disease are blood transfusion plus iron chelation (BTIC) therapy and bone marrow transplantation (BMT). Patients using these procedures experience different health-related quality of life (HRQoL). The purpose of the present study was to measure HRQoL in these patients using 2 different multiattribute quality of life (QoL) scales.

Methods: In this cross-sectional study, data were gathered using 3 instruments: a socio-demographic questionnaire, EQ-5D, and SF-36. A total of 196 patients with $\beta$-thalassemia were randomly selected from 2 hospitals in Shiraz (Southern Iran). Data were analyzed using logistic regression and multiple regression models to identify factors that affect the patients' HRQoL.

Results: The average EQ-5D index and EQ visual analog scale (VAS) scores were 0.86 (95\% CI: 0.83-0.89) and 71.85 (95\% CI: 69.13-74.58), respectively. Patients with BMT reported significantly higher EQ VAS scores ( 83.27 vs 68.55 , respectively). The results showed that patients who lived in rural area and patients with BMT reported higher EQ VAS scores (rural; $\beta=10.25, P=.006$ and BMT; $\beta=11.88, P=.000$ ). As well, SF-36 between 2 groups of patients were statistically significant in physical component scale (PCS).

Conclusion: Patients in the BMT group experienced higher HRQoL in both physical and mental aspects compared to those in the BTIC group. More studies are needed to assess the relative cost-effectiveness of these methods in developing countries.

Keywords: $\beta$-Thalassemia, Health Related Quality of Life (HRQoL), Blood Transfusion, Bone Marrow Transplantation (BMT)

Copyright: @ 2015 by Kerman University of Medical Sciences

Citation: Javanbakht M, Keshtkaran A, Shabaninejad H, Karami H, Zakerinia M, Delavari S. Comparison of blood transfusion plus chelation therapy and bone marrow transplantation in patients with $\beta$-thalassemia: application of SF-36, EQ-5D, and visual analogue scale measures. Int J Health Policy Manag. 2015;4(11):733740. doi:10.15171/ijhpm.2015.113
\end{abstract}

\section{Article History:}

Received: 2 January 2015

Accepted: 8 June 2015

ePublished: 13 June 2015

\section{*Correspondence to:}

Hassan Karami

Email: hassankarami92@yahoo.com

\section{Key Messages}

Implications for policy makers

- Given the limited resources of healthcare systems and existence of multiple approaches to the treatment for some diseases such as $\beta$-thalassemia, it is necessary to select a treatment procedure that has more utility and less cost.

- Since we aimed to compare quality of life between the two treatments and not quality adjusted life years, we did not take into account those people who died during the follow up.

- There is generally higher mortality associated with bone marrow transplantation (BMT) compared with transfusion and chelation which can decrease the total overall impact of BMT compared with transfusion and chelation.

- Costs of treatment were not calculated in this study and more studies are needed to decide about cost-effectiveness of these 2 therapies.

Implications for public

Knowing which treatments lead to the higher quality of life (QoL) is crucial for $\beta$-thalassemia patients. The present study gives details about QoL resulted from 2 therapeutic procedures. However, we should not choose a therapeutic method just based on higher QoL without considering mortality and cost-effectiveness and ease of access. 


\section{Introduction}

$\beta$-Thalassemia is the most common monogenic disorder in Mediterranean countries, parts of North and West Africa, Southeast Asia, and the Indian subcontinent. ${ }^{1}$ Its typical symptom is reduction or fault in the construction of the hemoglobin chain which leads to failure in the hematopoietic process. $^{2,3}$ This disease is specified by chronic and severe anemia manifestation, lack of proper growth, enlargement of the spleen, and liver and bone deformities, with especially visible changes in facial bones. ${ }^{4}$ It has been estimated that more than $25000 \beta$-thalassemia cases are living in Iran. The highest incidence is in the Caspian area in the north and in the Persian Gulf and Oman Sea area in the south. The incidence rate of this disease is $3-100 / 100000$ people. ${ }^{5}$ Treatment for $\beta$-thalassemia involves regular blood transfusion and disposal of excess iron from the body, especially liver. An alternative method is bone morrow transplantation (BMT) from healthy people. ${ }^{6}$ Long, regular and unpleasant therapeutic regimens influence all aspect of patients' lives, including mental health, social life, and health-related quality of life (HRQoL). ${ }^{7-12}$ Over the last 2 decades, there has been an increasing interest in assessment and improvement of HRQoL in patients with chronic diseases. ${ }^{13}$ In addition, due to limited resources in the healthcare systems, the demand for analyzing the costeffectiveness of treatments is increasing. ${ }^{14,15}$ One of the most important issues in economic evaluation is measuring and evaluating different aspects of a patient's HRQoL. ${ }^{15}$ Since all studies on HRQoL in $\beta$-thalassemia patients of Iran have focused on those who use blood transfusion, ${ }^{3,8,16-20}$ we decided to compare HRQoL in patients that use blood transfusion plus iron chelation (BTIC) therapy and those who have had bone marrow transplantation (BMT) using 2 different multiattribute quality of life (QoL) scales. In addition, we tried to assess the effects of different socio-economic characteristics on HRQoL.

\section{Methods}

Study Design and Subjects

We conducted a cross-sectional study on $\beta$-thalassemia patients who used BTIC and BMT in Shiraz province (Southern Iran). Two hundred ten subjects were selected from 2 hospitals using simple random sampling. The sample included BTIC patients who constantly visited the hospitals and had a medical record, BMT patients whose medical record and addresses or phone numbers were available, and patient with no congenital disease (160 users of BTIC and 50 users of BMT). All patients were listed in a Microsoft Excel sheet and then, based on random figures table, 160 users of BTIC and 50 patients who have undertaken BMT were selected. From the selected patients 6 in BMT and 8 in BTIC group were not able to attend in the study because of death of BMT patients, change in address, and unwillingness to participate in the study. All remaining subjects signed an informed consent form. All the selected patients were asked to fill out SF-36 and EQ-5D questionnaires by a trained investigator. In the cases that patients do not have enough literacy to understand questionnaire's items and for the children, the questionnaire completed through interview with patient. Before filling out the questionnaires or performing interviews, the patients received information about the purpose and applications of the research. QoL data for BMT patients were collected between 8 months and 18 years after BMT. For BTIC patients questionnaire were filled in the time they refer for blood transfusion. Patients with less than $50 \%$ of national average income were classified as low-income level, and patients with higher $50 \%$ of national average, were classified as highincome group. The remaining were classified as middleincome group. In the end, valid questionnaires were collected from 196 patients (152 BTIC and 44 BMT patients).

\section{Measures}

Data were gathered using 3 instruments: a socio-demographic questionnaire, the validated Persian version of EQ-5D 3L, EQ visual analog scale (VAS), and SF-36. ${ }^{21}$ EQ-5D is one of the general tools for measuring QoL. It has 2 parts. The first part contains 5 questions about mobility (MO), self-care (SC), usual activities (UA), pain/discomfort (P/D) and anxiety/ depression (A/D). Each question has 3 possible answers, including no problem, some or moderate problem, and severe or extreme problem. In this study, due to the absence of a locally set of values, as suggested by EuroQoL Group, the EQ$5 \mathrm{D}$ index score was calculated using the UK EQ VAS value set. The second part (EQ VAS) is a graded tool for health status where the respondents select a score from 0 to 100 to represent their level of health, with higher scores indicating better QoL. ${ }^{15,22,23}$ Short Form Health Survey (SF-36) is another instrument used for assessing general health of $\beta$-thalassemia patients. This is also a general tool for measuring QoL in different contexts. ${ }^{24}$ SF-36 assesses general health in eight dimensions: physical functioning (PF), role physical (RP), bodily pain (BP), general health $(\mathrm{GH})$, role emotional (RE), social functioning (SF), vitality (VA), and mental health $(\mathrm{MH})$. The mean of these dimensions is calculated from 0 to 100 , with 0 and 100 indicating the worst and the best health conditions, respectively. ${ }^{8}$

\section{Data Analysis}

Continuous variables were presented by mean and standard deviation (SD) and discrete variables were reported in absolute numbers and percentages. Responses to the EQ-5D dimensions were dichotomized to having problem or not and were analysed using logistic regression. Also the factors affecting QoL were identified using multiple regression models, where the EQ-5D index score was the dependent variable and the effect of each independent variable on QoL was calculated. SF-36 scores were also compared for BTIC and BMT patients, and multiple linear regression models were used for analyzing the effect of independent variables on 8 dimensions of SF-36. All analyses were done in STATA/ SE 12.0.

\section{Results}

The patients' characteristics are shown in Table 1. Patients' age varied from 5 to 35 years and the average age of respondents was 20 years ( $\mathrm{SD}=7.49) .58 .16 \%$ of the respondents were male. About $83 \%$ of the patients had less than 12 th grade education, and $39 \%, 28 \%$, and $33 \%$ of the participants were in the low-, middle-, and high-income groups, respectively. Moreover, comparison of demographic characteristics between the 2 groups (BTIC and BMT) showed significant differences only 
in the level of income and residence indicators $(P<.05)$.

EQ-5D Descriptive

Overall, $3.57 \%, 2.04 \%, 3.57 \%, 32.14 \%$, and $28.57 \%$ of the

$\beta$-thalassemia patients reported "some or extreme problems" in $\mathrm{MO}, \mathrm{S} / \mathrm{C}, \mathrm{UA}, \mathrm{P} / \mathrm{D}$, and $\mathrm{A} / \mathrm{D}$ dimensions of the EQ-5D index, respectively (Table 2). Patients less than 18 years old were significantly different in S/C and A/D dimensions than other age groups. Patients who lived in urban areas had more problems in all the dimension of EQ-5D, except MO.

Table 1. The Characteristics of the Patients

\begin{tabular}{|c|c|c|c|c|c|c|c|}
\hline \multirow{2}{*}{ Variable } & \multicolumn{2}{|c|}{ Total } & \multicolumn{2}{|c|}{ BTIC } & \multicolumn{2}{|c|}{ BMT } & \multirow[t]{2}{*}{$P$} \\
\hline & No. & $\%$ & No. & $\%$ & No. & $\%$ & \\
\hline \multicolumn{8}{|l|}{ Gender } \\
\hline Male & 114 & 58.16 & 90 & 59.21 & 24 & 54.54 & \multirow{2}{*}{.581} \\
\hline Female & 82 & 41.84 & 62 & 40.79 & 20 & 45.46 & \\
\hline \multicolumn{8}{|l|}{ Age group } \\
\hline$<18$ & 73 & 37.24 & 55 & 36.18 & 18 & 40.90 & \multirow{3}{*}{.748} \\
\hline $18-25$ & 67 & 34.18 & 54 & 35.52 & 13 & 29.54 & \\
\hline$\geq 25$ & 56 & 28.58 & 43 & 28.30 & 13 & 29.56 & \\
\hline \multicolumn{8}{|c|}{ Education (y) } \\
\hline$\leq 12$ & 163 & 83.16 & 127 & 83.55 & 36 & 81.81 & \multirow{2}{*}{.787} \\
\hline$>12$ & 33 & 16.84 & 25 & 16.45 & 8 & 18.19 & \\
\hline \multicolumn{8}{|l|}{ Income } \\
\hline Low & 77 & 39.28 & 71 & 46.71 & 6 & 13.63 & \multirow{3}{*}{$<.001$} \\
\hline Middle & 55 & 28.06 & 42 & 27.63 & 13 & 29.54 & \\
\hline High & 64 & 32.66 & 39 & 25.66 & 25 & 56.83 & \\
\hline \multicolumn{8}{|c|}{ Living place } \\
\hline Urban & 175 & 89.28 & 140 & 92.10 & 35 & 79.54 & \multirow{2}{*}{.018} \\
\hline Rural & 21 & 10.72 & 12 & 7.90 & 9 & 20.46 & \\
\hline \multicolumn{8}{|c|}{ Supplementary Insurance } \\
\hline Yes & 47 & 23.98 & 37 & 24.34 & 10 & 22.72 & \multirow{2}{*}{.825} \\
\hline No & 149 & 76.02 & 115 & 75.66 & 34 & 77.28 & \\
\hline
\end{tabular}

Abbreviations: BTIC, blood transfusion plus iron chelation; BMT, bone marrow transplantation.

Table 2. Results of the EQ-5D Descriptive

\begin{tabular}{|c|c|c|c|c|c|c|c|c|c|c|}
\hline \multirow[b]{2}{*}{ Variables } & \multicolumn{2}{|c|}{ Mobility } & \multicolumn{2}{|c|}{ Self-Care } & \multicolumn{2}{|c|}{ Usual Activities } & \multicolumn{2}{|c|}{ Pain/Discomfort } & \multicolumn{2}{|c|}{ Anxiety/Depression } \\
\hline & $\begin{array}{c}\% \text { Reporting } \\
\text { any Problems }\end{array}$ & $P$ & $\begin{array}{c}\text { \% Reporting } \\
\text { any Problems }\end{array}$ & $P$ & $\begin{array}{c}\text { \% Reporting } \\
\text { any Problems }\end{array}$ & $P$ & $\begin{array}{c}\% \text { Reporting } \\
\text { any Problems }\end{array}$ & $P$ & $\begin{array}{c}\% \text { Reporting } \\
\text { any Problems }\end{array}$ & $P$ \\
\hline \multicolumn{11}{|l|}{ Gender } \\
\hline Male & 5.26 & .132 & 3.51 & .087 & 5.26 & .132 & 32.46 & .912 & 28.95 & .891 \\
\hline Female & 1.22 & & 0.00 & & 1.22 & & 31.71 & & 28.05 & \\
\hline \multicolumn{11}{|l|}{ Age group } \\
\hline$<18$ & 6.85 & .093 & 5.48 & .032 & 6.85 & .093 & 26.03 & .344 & 15.07 & .005 \\
\hline $18-25$ & 0.00 & & 0.00 & & 0.00 & & 34.33 & & 38.81 & \\
\hline$\geq 25$ & 3.57 & & 0.00 & & 3.57 & & 37.50 & & 33.93 & \\
\hline \multicolumn{11}{|l|}{ Education (y) } \\
\hline$\leq 12$ & 4.29 & & 2.45 & & 4.29 & & 33.74 & & 26.38 & \\
\hline$>12$ & 0.00 & .225 & 0.00 & .363 & 0.00 & .225 & 24.24 & .287 & 39.39 & .131 \\
\hline \multicolumn{11}{|l|}{ Income } \\
\hline Low & 3.90 & .101 & 3.90 & .280 & 3.90 & .689 & 24.68 & .172 & 33.77 & .406 \\
\hline Middle & 7.27 & & 0.00 & & 1.82 & & 34.55 & & 23.64 & \\
\hline High & 0.00 & & 1.56 & & 4.69 & & 39.06 & & 26.56 & \\
\hline \multicolumn{11}{|l|}{ Living place } \\
\hline Urban & 3.43 & .756 & 2.29 & .484 & 4.00 & .351 & 33.14 & .387 & 32.00 & .002 \\
\hline Rural & 4.76 & & 0.00 & & 0.00 & & 23.81 & & 0.00 & \\
\hline \multicolumn{11}{|l|}{ Insurance } \\
\hline Yes & 0.00 & .130 & 2.13 & .961 & 4.26 & .772 & 34.04 & .749 & 25.53 & .597 \\
\hline No & 4.70 & & 2.01 & & 3.36 & & 31.54 & & 29.53 & \\
\hline \multicolumn{11}{|l|}{ Treatment } \\
\hline BTIC & 3.95 & .598 & 1.97 & .902 & 3.59 & .598 & 26.32 & .001 & 34.87 & $<.001$ \\
\hline BMT & 2.27 & & 2.27 & & 2.27 & & 52.27 & & 6.82 & \\
\hline Total & 3.57 & & 2.04 & & 3.57 & & 32.14 & & 28.57 & \\
\hline
\end{tabular}

Abbreviations: BTIC, blood transfusion plus iron chelation; BMT, bone marrow transplantation.

Notes: $P$-value: chi-squared test; No sign: not significant. 
Furthermore, the frequency of "some or extreme problems" responses to $\mathrm{MO}, \mathrm{UA}$, and $\mathrm{A} / \mathrm{D}$ dimensions was higher in the BTIC group, and respondents with BMT had more problems in $S C$ and $P / D$. However, these differences were significant in $\mathrm{P} / \mathrm{D}$ and $\mathrm{A} / \mathrm{D}$. EQ-5D Index and VAS Scores.

The average EQ-5D index and EQ VAS scores were 0.86 (95\% CI: $0.83-0.89$ ) and 71.85 (95\% CI: 69.13-74.58), respectively (Table 3). There were significant differences between the EQ VAS scores of different income groups, with the high-income group having the highest scores. The results also showed that BMT patients had significantly higher EQ VAS score than BTIC patients ( 83.27 vs 68.55 , respectively). Finally, there was significant differences in EQ VAS score between patients of different residence groups.

\section{Regression Analysis}

Multivariate logistic regression analysis was used for EQ5D index and EQ VAS scores (Table 4). As the data show, EQ VAS scores were significantly associated with residence and treatment approach; that is, patients living in rural area and patients receiving BMT reported higher EQ VAS scores (rural; $\beta: 10.25, P=.006$ and BMT; $\beta: 11.88, P=.000$ ).

\section{SF-36 Scores and Regression Analysis}

In this study, SF-36 scores were also used to compare the health of patients who received each of the 2 treatment approaches (Table 5). The results show significant differences between the 2 groups in PF, RE, and RP dimensions of SF- 36. As well, SF-36 between 2 groups of patients were statistically significant in physical component scale (PCS).

Multiple linear regression was applied to SF-36 scores (Table
6). As Table 6 shows, patients receiving BMT had higher SF36 scores (PF; $\beta$ : 9.11, RP; $\beta$ : 16.85, BP; $\beta$ : -2.14 , GH; $\beta$ : 4.27, $\mathrm{MH} ; \beta$ : 4.41, RE; $\beta: 22.45$, SF; $\beta$ : 7.22, VA; $\beta$ : 4.44, PCS; $\beta$ : 3.37 , MCS; $\beta$ : 4.11). The data also show that type of treatment was significantly associated with SF-36 scores.

\section{Discussion}

To our best knowledge, all studies on the QoL of patients with $\beta$-thalassemia in Iran were done with patients who received blood transfusion and iron chelation therapy. ${ }^{3,8,16-20}$ This study is the first to investigate and compare QoL in patients receiving blood transfusion and bone morrow transplantation. Iran is one of the pioneers in using BMT for $\beta$-thalassemia patients, ${ }^{25}$ and thus this study can be remarkable. EQ-5D and SF-36 were used to examine the patient's HRQoL, then scores resulted from 2 questionnaires were compared. Also, the relation between dimensions of the questionnaires and patient's characteristics were examined. SF-36 has been used in many countries to study HRQoL in patients with $\beta$-thalassemia. ${ }^{8,16,26,27}$ EQ-5D has also been used in several other studies. ${ }^{10,11,26}$ In the present study, EQ-5D was used for 2 reasons; using this questionnaire allows for converting utility scores into quality-adjusted life-years (QALYs), and the questionnaire is simple and does not need much time to complete. ${ }^{15}$ Using EQ-5D index, the results of this study showed that patient with $\beta$-thalassemia (both groups) had many "problems" in different dimensions of the scale, ranging from $2.04 \%$ to $32.14 \%$, and these problems have the highest rate in $\mathrm{P} / \mathrm{D}$ and $\mathrm{A} / \mathrm{D}$ dimensions. The results indicated that there was no significant difference between BMT and BTIC groups in SC, MO, and UA dimensions. However, significant

Table 3. Results of EQ-5D Index and EQ VAS Scores

\begin{tabular}{|c|c|c|c|c|c|c|c|c|}
\hline \multirow{2}{*}{ Indicator } & \multicolumn{4}{|c|}{ EQ-5D Index Score } & \multicolumn{4}{|c|}{ EQ VAS } \\
\hline & Mean & \multicolumn{2}{|c|}{$95 \% \mathrm{Cl}$} & $P$ & Mean & \multicolumn{2}{|c|}{$95 \% \mathrm{Cl}$} & $P$ \\
\hline \multicolumn{9}{|l|}{ Gender } \\
\hline Male & 0.85 & 0.80 & 0.89 & .221 & 70.86 & 67.09 & 74.62 & .401 \\
\hline Female & 0.88 & 0.85 & 0.92 & & 73.23 & 69.21 & 77.25 & \\
\hline \multicolumn{9}{|l|}{ Age group } \\
\hline$<18$ & 0.88 & 0.83 & 0.93 & .584 & 72.97 & 68.38 & 77.57 & .910 \\
\hline $18-25$ & 0.85 & 0.80 & 0.89 & & 72.63 & 68.07 & 77.18 & \\
\hline$\geq 25$ & 0.85 & 0.80 & 0.91 & & 69.46 & 64.39 & 74.54 & \\
\hline \multicolumn{9}{|c|}{ Years of school } \\
\hline$\leq 12$ & 0.86 & 0.83 & 0.89 & & 71.85 & 68.75 & 74.96 & \\
\hline$>12$ & 0.85 & 0.77 & 0.93 & .740 & 71.85 & 66.04 & 77.66 & 999 \\
\hline \multicolumn{9}{|l|}{ Income } \\
\hline Low & 0.88 & 0.83 & 0.92 & .592 & 68.39 & 64.05 & 72.73 & $.042^{\mathrm{a}}$ \\
\hline Middle & 0.84 & 0.78 & 0.91 & & 71.16 & 65.68 & 76.65 & \\
\hline High & 0.85 & 0.81 & 0.90 & & 76.61 & 72.30 & 80.92 & \\
\hline \multicolumn{9}{|l|}{ Urbanity } \\
\hline Urban & 0.85 & 0.82 & 0.89 & .175 & 70.54 & 67.62 & 73.46 & .006 \\
\hline Rural & 0.92 & 0.84 & 1.00 & & 82.81 & 76.06 & 89.56 & \\
\hline \multicolumn{9}{|c|}{ Supplementary insurance } \\
\hline Yes & 0.85 & 0.78 & 0.91 & .638 & 71.79 & 66.92 & 76.66 & $.979^{a}$ \\
\hline No & 0.86 & 0.83 & 0.90 & & 71.87 & 68.58 & 75.17 & \\
\hline \multicolumn{9}{|l|}{ Treatment } \\
\hline BTIC & 0.87 & 0.84 & 0.90 & .450 & 68.55 & 65.44 & 71.65 & $.000^{\mathrm{a}}$ \\
\hline BMT & 0.84 & 0.76 & 0.92 & & 83.27 & 78.66 & 87.89 & \\
\hline Total & 0.86 & 0.83 & 0.89 & & 71.85 & 69.13 & 74.58 & \\
\hline
\end{tabular}

Abbreviations: BTIC, blood transfusion plus iron chelation; BMT, bone marrow transplantation; VAS, visual analog scale.

a Statistically significant at $P<.05$; No signs: No significant. 
Table 4. Results of Multiple Regression Analysis

\begin{tabular}{|c|c|c|c|c|c|c|}
\hline \multirow{2}{*}{ Indicator } & \multicolumn{3}{|c|}{ EQ-5D Index Score } & \multicolumn{3}{|c|}{ EQ VAS Score } \\
\hline & Coef & SE & $P$ & Coef & SE & $P$ \\
\hline \multicolumn{7}{|l|}{ Gender } \\
\hline Male & Ref & & & Ref & & \\
\hline Female & 0.05 & 0.03 & .119 & 1.77 & 2.68 & .509 \\
\hline \multicolumn{7}{|l|}{ Age group } \\
\hline$<18$ & Ref & & & Ref & & \\
\hline$\geq 25$ & -0.04 & 0.04 & .292 & -4.10 & 3.57 & .251 \\
\hline \multicolumn{7}{|c|}{ Years of school } \\
\hline$\leq 12$ & Ref & & & Ref & & \\
\hline$>12$ & -0.01 & 0.04 & .851 & 0.70 & 3.13 & .824 \\
\hline \multicolumn{7}{|l|}{ Income } \\
\hline Low & Ref & & & Ref & & \\
\hline Middle & -0.03 & 0.04 & .470 & 1.20 & 3.96 & .762 \\
\hline High & -0.02 & 0.05 & .725 & 4.83 & 3.61 & .182 \\
\hline \multicolumn{7}{|l|}{ Urbanity } \\
\hline Urban & Ref & & & Ref & & \\
\hline Rural & 0.07 & 0.04 & .086 & 10.25 & 3.70 & .006 \\
\hline \multicolumn{7}{|c|}{ Supplementary insurance } \\
\hline Yes & Ref & & & Ref & & \\
\hline No & 0.00 & 0.04 & .994 & -0.19 & 3.13 & .951 \\
\hline \multicolumn{7}{|l|}{ Treatment } \\
\hline BTIC & Ref & & & Ref & & \\
\hline BMT & -0.04 & 0.05 & .498 & 11.88 & 3.31 & .000 \\
\hline
\end{tabular}

Abbreviations: BTIC, blood transfusion plus iron chelation; BMT, bone marrow transplantation; VAS, visual analog scale.

Notes: No signs: No significant.

Table 5. Comparison of SF-36 Scores Between BMT and BTIC Patients

\begin{tabular}{lccccc}
\hline \multirow{2}{*}{ SF-36 } & \multicolumn{2}{c}{ BTIC } & \multicolumn{2}{c}{ BMT } & \multirow{2}{*}{$\boldsymbol{P}$} \\
\cline { 2 - 5 } Subscales & Mean & SD & Mean & SD & \\
\hline PF & 84.93 & 17.60 & 93.07 & 10.90 & $.004^{\mathrm{a}}$ \\
RP & 58.88 & 38.32 & 77.84 & 29.14 & $.003^{\mathrm{a}}$ \\
BP & 81.68 & 20.09 & 81.36 & 20.82 & .928 \\
GH & 64.24 & 21.82 & 68.41 & 20.22 & .259 \\
MH & 65.66 & 19.78 & 70.55 & 15.48 & .133 \\
RE & 55.92 & 40.35 & 78.79 & 39.43 & $.001^{\mathrm{a}}$ \\
SF & 80.02 & 21.35 & 86.93 & 20.70 & .058 \\
VT & 65.89 & 18.24 & 69.89 & 16.96 & .195 \\
PCS & 48.23 & 7.09 & 51.65 & 6.60 & $.005^{\mathrm{a}}$ \\
MCS & 45.19 & 9.76 & 49.53 & 9.59 & .010 \\
\hline Abbreviationnnn
\end{tabular}

Abbreviations: RP, role limitations; PF, physical functioning; $\mathrm{BP}$, bodily pain; $\mathrm{GH}$, general health; VT, Vitality; RE, role limitations; $\mathrm{MH}$, mental health; MCS, mental component scale; PCS, physical component scale; SF, social functioning; BTIC, blood transfusion plus iron chelation; BMT, bone marrow transplantation.

a Statistically significant at $P<.05$.

differences were observed in $\mathrm{P} / \mathrm{D}$ and $\mathrm{A} / \mathrm{D}$ dimensions. In terms of $\mathrm{P} / \mathrm{D}$, a higher percentage of $\mathrm{BMT}$ patients complained about blood transfusion methods ( $52.27 \%$ vs $26.32 \%$ ), while a higher percentage of BTIC patients complained about A/D ( $34.87 \%$ to $6.82 \%)$. Review of the literature showed that the most common complaints have been related to $\mathrm{P} / \mathrm{D}$ and A/D. ${ }^{10,11}$ For instance, Shaligram et $\mathrm{al}^{10}$ and Mantovani et $\mathrm{al}^{11}$ reported similar results in patients who received blood transfusion. However, the most common complaint reported in these studies was related to the P/D dimension $(64 \%$ and $60.5 \%$, respectively), while in our study the most common complaint was related to the A/D dimension (34.87\%). Problems related to A/D in cited studies were similar to our findings (33\%, 39.5\%, and 34.87\%). In Shaligram et al, ${ }^{10} \mathrm{a}$ higher percentage of patients had problems was much with the MO dimension that the patients studied in the present research (33\% vs 3.95\%). Therefore, these findings suggest that patients who receive blood transfusion have more $\mathrm{A} / \mathrm{D}$ problems and require more attention. Regarding that estimation of EQ-5D score is only based on all dimension values, we were not able to do further analysis on the dimensions that are significantly different between 2 groups. The average EQ-5D index scores of BTIC and BMT patients were 0.87 and 0.84 , respectively. The average EQ-5D index score of all the patients was 0.86 , and there were no significant differences between these groups in EQ-5D index score. As EQ-5D includes only 5 dimensions of health it may not be the ideal and very sensitive measure to evaluate thalassemia patients health, but it is a general instrument to measure QALY by many organization like the National Institute for Health and Care Excellence (NICE). However, the average EQ VAS scores of BTIC and BMT patients were $68.55 \%$ and $83.27 \%$, respectively. This significant difference may be due to the fact that BMT patients do not experience the regular and long-term blood transfusion and iron chelation that BTIC patients undergo. Also the difference between EQ-5D and VAS could be explained partially by the dimensions of health which are not included in EQ-5D but will be considered subjectively by the patients in their evaluation using VAS. In a similar study by Mantovani et al, ${ }^{11}$ the average EQ VAS score of BTIC patients was 73, which could be due to timely and appropriate chelation therapy and access to treatment, support, and complete insurance coverage in that context (Italy). The present findings showed that $15.07 \%, 38.81 \%$, and $33.93 \%$ of the subjects in the age groups of $<18,18-25$ and $\geq 25$ had A/D problems. Moreover, rural and urban patients were 
Table 6. Multiple Linear Regression Model for SF-36 Scores

\begin{tabular}{|c|c|c|c|c|c|c|c|c|c|c|}
\hline Variables & PF & RP & BP & GH & MH & RE & SF & VA & PCS & MCS \\
\hline \multicolumn{11}{|l|}{ Gender } \\
\hline Male & Ref & & & & & & & & & \\
\hline Female & 1.14 & 1.97 & 0.17 & 1.63 & 2.17 & 5.82 & -2.01 & -0.91 & -0.47 & 1.80 \\
\hline \multicolumn{11}{|l|}{ Age group } \\
\hline$<18$ & Ref & & & & & & & & & \\
\hline $18-25$ & $9.23^{a}$ & 2.37 & -2.15 & 3.78 & -3.10 & 7.46 & -0.39 & -3.28 & 2.04 & -2.57 \\
\hline \multicolumn{11}{|c|}{ Years of school } \\
\hline$\leq 12$ & Ref & & & & & & & & & \\
\hline$>12$ & -2.91 & -0.58 & 0.33 & 1.07 & -4.57 & 8.89 & -2.43 & -2.82 & -0.14 & -1.02 \\
\hline \multicolumn{11}{|l|}{ Income } \\
\hline Low & Ref & & & & & & & & & \\
\hline Middle & -1.75 & 5.23 & 0.53 & 0.09 & 1.87 & 9.08 & -0.88 & -0.87 & 0.04 & 0.69 \\
\hline \multicolumn{11}{|l|}{ Urbanity } \\
\hline Urban & Ref & & & & & & & & & \\
\hline Rural & 0.27 & -3.06 & 4.72 & 6.10 & 5.41 & -3.11 & 7.57 & 1.67 & -0.32 & 2.04 \\
\hline \multicolumn{11}{|c|}{ Supplementary insurance } \\
\hline Yes & Ref & & & & & & & & & \\
\hline No & -0.57 & -9.46 & $7.4^{b}$ & 3.11 & -1.44 & $-4.5^{a}$ & -0.02 & -1.30 & 1.82 & $-3.31^{a}$ \\
\hline \multicolumn{11}{|l|}{ Treatment } \\
\hline BTIC & Ref & & & & & & & & & \\
\hline BMT & $9.11^{\mathrm{a}}$ & $16.85^{\mathrm{a}}$ & $-2.14^{\mathrm{a}}$ & $4.27^{\mathrm{a}}$ & $4.41^{a}$ & $22.45^{\mathrm{a}}$ & 7.22 & 4.44 & $3.37^{\mathrm{a}}$ & $4.11^{\mathrm{a}}$ \\
\hline
\end{tabular}

Abbreviations: RP, role limitations due to physical problems; PF, physical functioning; BP, bodily pain; GH, general health; VT, Vitality; RE, role limitations due to emotional problems; $\mathrm{MH}$, mental health; MCS, mental component scale; PCS, physical component scale; SF, social functioning; BTIC, blood transfusion plus iron chelation; BMT, bone marrow transplantation.

a $P<.05$.

${ }^{\mathrm{b}} P<.1$.

significantly different in this dimension, indicating that age and residence have a significant effect on the HRQoL of patients with $\beta$-thalassemia. Also there were significant differences between patients with low-, middle-, and highincome as well as patients in rural and urban areas in EQ VAS score. Multiple regression analysis for EQ-5D index showed that there was no significant correlation between demographic characteristics and therapeutic methods. Although EuroQol Group recommended to use UK value set in case, there is no local one but QoL is heavily depend on the socio-economic and cultural structure of each society and using value set from other countries may create biased result. However, there was a significant correlation between residence and therapeutic methods in EQ VAS. The average SF-36 scores of BTIC patients suggested that these patients had the highest physical function, which is similar to the results of similar studies conducted in Iran. ${ }^{8,16-20}$ Furthermore, in a study by Yengil et $\mathrm{al}^{28}$ the BP dimension took the highest score after the SF dimension. Based on the results of this study, RE had the weakest function among other dimensions, which is consistent with other studies done in Iran. ${ }^{8,16}$ The mean of this dimension in Safizadeh et $\mathrm{al}^{19}$ was similar to our study, but RE was not the weakest dimension in their study. Contrary to these, the best function of RE were seen in Baraz Pordanjani's study, ${ }^{17}$ and Haghpanah et $\mathrm{al}^{18}$ showed that it has the greatest effect after physical functioning. The patients in our study had lower RE function compared to other dimensions. This is consistent with the results of Safizadeh et $\mathrm{al}^{19}$ and Khani et al. ${ }^{8}$ Moreover, the mean of physical and mental dimensions in the present study were similar to those reported by Mantovani et $\mathrm{al},{ }^{11}$ but lower than those reported by Haghpanah et al. ${ }^{18}$ In addition, we found that the patients' functionality in almost all the dimensions decreased with age. With increasing age as well as physical problems and functional limitation, patients encounter other problems such as extending family size, continuing education, and finding a good job, which will result in various psychological problems. ${ }^{16}$ Overall, comparing BTIC and BMT patients showed that regardless of physical pain which was similar in these groups, BMT patients had better functionality in all the other dimensions. The results also showed significant differences between the 2 groups in PF, RP, and RE, with higher scores in BMT patients. It seems that leaving regular blood transfusion that causes iron overloading and subsequent physical problems, not having to regularly visit medical centers, and not having to undergo blood transfusion and iron chelation therapy which may lead to absence from work or school and therefore loss of selfconfidence can positively affect patients' morale and improve their mental health. Also as the data were collected during time BTIC patient refer for blood transfusion while BMT group were collected 8 months to 18 years after BMT, different timing may also explain why BMT had higher QOL. Multiple linear regression analysis was used to eliminate the effect of confounding factors ${ }^{19}$ and showed that age, level of supplementary insurance, and therapeutic methods are associated with patients' HRQoL. Although there might be other relevant variables such as diabetes mellitus (DM), hypogonadism, cardiomyopathy, graft-versus-host disease, etc. that may affect the QoL, but, patients medical records were incomplete and data about these factors were not valid to be included in the model. Safizadeh et $\mathrm{al}^{19}$ found gender differences in patients' QoL, but unlike this study, found no 
significant effect for age. However, a study conducted in Thailand showed that age was associated with HRQoL.? Moreover, Cheuk et $\mathrm{al}^{9}$ showed that BMT patients have higher QoL, especially in the physical dimension, which is consistent with the result of our study. Furthermore, Lawson et $\mathrm{al}^{29}$ argued that BMT is the only way of treatment and achieving QoL in major thalassemia patients. Consistent with previous studies, our findings showed that BTIC patients have lower physical problems than mental problems, ${ }^{11}$ and BMT patients have higher scores in physical and psychosocial domains. ${ }^{9}$ However, more studies need to be done with a costeffectiveness approach to help policy makers in BTIC or BMT development across the country.

\section{Conclusion}

It seems that BMT provides higher HRQoL in patients with $\beta$-Thalassemia, both in physical and mental aspects. Using analysis of multiple regression test, we found no significant correlation between EQ-5D index scores, demographic parameters, and treatment methods. However, residence (urban or rural) and type of treatment were significantly associated with health (HRQoL, EQ VAS). Furthermore, SF-36 scores showed significant differences between BTIC and BMT patients in RP, RE, PF, and PCS. Since patients' age is combined in the analysis, such approach may have limitations such as heterogeneity in the QoL assessments; and ratings from young children may not be combinable with ratings for older children and adults. Also since this study is the first research on QoL of BMT $\beta$-thalassemia patients in Iran, further investigation is needed to confirm the results of our study, which proposes BMT as the preferred method for treating patients with $\beta$-thalassemia.

\section{Acknowledgments}

The present article was extracted from the thesis written by Hassan Karami and was financially supported by Shiraz University of Medical Sciences, Shiraz, Iran (grant No. 6292). The authors would like to thank all participants in the study.

\section{Ethical issues}

The study was approved by the Ethics Committee of Shiraz University of Medical Sciences, Shiraz, Iran.

\section{Competing interests}

The authors declare that they have no competing interests.

\section{Authors' contributions}

$\mathrm{MJ}, \mathrm{AK}, \mathrm{MZ}$, and $\mathrm{HK}$ contributed to conceiving and designing the study. The data was collected by $\mathrm{HK}$; and was analyzed and interpreted jointly by MJ and HK. All authors contributed equally in writing the manuscript. All authors reviewed and approved the final manuscript.

\section{Authors' affiliations}

${ }^{1}$ Health Economics Research Unit, Institute of Applied Health Sciences, University of Aberdeen, Aberdeen, UK. ${ }^{2}$ Health Economics Department, School of Management and Information Sciences, Shiraz University of Medical Sciences, Shiraz, Iran. ${ }^{3}$ Department of Health Services Management, School of Health Management and Information Sciences, Iran University of Medical Sciences, Tehran, Iran. ${ }^{4}$ Health Management and Economics Research Center, Iran University of Medical Sciences, Tehran, Iran. ${ }^{5}$ Department of Internal Medicine, BMT Unit, Hematology Research Center, and Organ Transplant Research Center, Nemazee Hospital, Shiraz University of Medical Sciences, Shiraz, Iran. ${ }^{6}$ Department of Health Management and Economics, School of
Public Health, Tehran University of Medical Sciences, Tehran, Iran.

\section{Reference}

1. Modell B, Darlison M. Global epidemiology of haemoglobin disorders and derived service indicators. Bull World Health Organ. 2008;86:480-487.

2. Karami $\mathrm{H}$, Kosaryan $\mathrm{M}$, Abolghasemi $\mathrm{H}$, et al. Deferiprone plus deferoxamine versus deferoxamine iron chalation in beta thalassemia major. Sci J Iran Blood Transfus Organ. 2011;7(4):227-234

3. Imani E, Asadi Nooghabi F, Hosseini Teshnizi S, Yosefi P, Salari F. Comparison quality of life in patients with thalassemia major based on participating in group activities, Bandar Abbas. Sci J Iran Blood Transfus Organ. 2013;10(2):198-206.

4. Kasper D, Fauci A, Longo D, Braunwald E, Hauser S, Jameson J. Harrison's Principles of Internal Medicine: McGraw-Hill; 2005.

5. Keshtkaran A, Javanbakht M, Salavati S, Mashayekhi A, Karimi M, Nuri B. Cost-utility analysis of oral deferasirox versus infusional deferoxamine in transfusion-dependent betathalassemia patients. Transfusion. 2013;53(8):1722-1729. doi:10.1111/trf. 12024

6. Ministry of Health. Comprehensive guidelines and educational materials national prevention program of beta thalassemia. Tehran: Center of publishing sound; 2004.

7. Thavorncharoensap M, Torcharus K, Nuchprayoon I, Riewpaiboon A, Indaratna K, Ubol BO. Factors affecting healthrelated quality of life in Thai children with thalassemia. BMC Blood Disord. 2010;10:1. doi:10.1186/1471-2326-10-1

8. Khani Hý, Majdi MRý, Azad Marzabadi Eý, Montazeri Aý, Ghorbani Aý, Ramezani Mý. Quality of life in Iranian Betathalassemia major patients of ýsouthern coastwise of the Caspian Sea. J Behav Sci. 2009;2(4):325-332.

9. Cheuk DK, Mok AS, Lee AC, et al. Quality of life in patients with transfusion-dependent thalassemia after hematopoietic SCT. Bone Marrow Transplant. 2008;42(5):319-327. doi:10.1038/ bmt.2008.165

10. Shaligram D, Girimaji S, Chaturvedi S. Psychological problems and quality of life in children with thalassemia. Indian J Pediatr. 2007;74:727-730.

11. Mantovani LG, Scalone L, Ravera S, Rofail D, Cappellini MD. Quality of Life and Satisfaction with Iron Chelation Therapy in Patients with Beta Thalassemia Major: Results from the ITHACA Study. ASH Annual Meeting Abstracts. 2006;108(11):3344.

12. Allahyari A, Alhany F, Kazemnejad A, Izadyar M. The effect of family-centered empowerment model on the Quality of Life of school-age B-thalassemic children. Iranian Journal of Pediatrics. 2006;16(4):455-461.

13. Uyl-de Groot CA, Buijt I, Gloudemans IJ, Ossenkoppele GJ, Berg HP, Huijgens PC. Health related quality of life in patients with multiple myeloma undergoing a double transplantation. Eur J Haematol. 2005;74(2):136-143. doi:10.1111/j.16000609.2004.00346.x

14. Lee AJ, Morgan CL, Conway P, Currie CJ. Characterisation and comparison of health-related quality of life for patients with renal failure. Curr Med Res Opin. 2005;21(11):1777-1783. doi:10.1185/030079905x65277

15. Javanbakht M, Abolhasani F, Mashayekhi A, Baradaran HR, Jahangiri Noudeh $Y$. Health related quality of life in patients with type 2 diabetes mellitus in Iran: a national survey. PLoS One. 2012;7(8):e44526. doi:10.1371/journal.pone.0044526

16. Hadi N, Karami D, Montazeri A. Health-related quality of life in major thalassemic patients. journal of the Iranian Institute for Health Sciences Research. 2009;8(4):387-393.

17. Baraz Pordanjani S, Zare K, Pedram M, Pakbaz Z. Comparison of quality of life of thalassemic children with their parents. Sci 
Med J. 2010;8(4):456-462.

18. Haghpanah S, Nasirabadi S, Ghaffarpasand F, et al. Quality of life among Iranian patients with beta-thalassemia major using the SF-36 questionnaire. Sao Paulo Med J. 2013;131(3):166172.

19. Safizadeh H, Farahmandinia Z, Nejad SS, Pourdamghan N, Araste M. Quality of life in patients with thalassemia major and intermedia in Kerman-Iran. Mediterr J Hematol Infect Dis. 2012;4(1):e2012058. doi:10.4084/mjhid.2012.058

20. Azarkeivan A, Hajibeigi B, Alavian SM, Lankarani MM, Assari S. Associates of poor physical and mental health-related quality of life in beta thalassemia-major/intermedia. $J$ Res Med Sci. 2009;14(6):349-355.

21. Montazeri A, Goshtasebi A, Vahdaninia M, Gandek B. The Short Form Health Survey (SF-36): translation and validation study of the Iranian version. Qual Life Res. 2005;14(3):875-882.

22. Goudarzi R, Akbari Sari A, Zeraati H, Rashidian A, Mohammad K. Population-based preference weights for EQ-5D Health States using visual analogue scale (VAS) in Iran. Iranian Red Crescent Medical Journal 2015; forthcoming.

23. Adib-Hajbaghery $M$, Abasinia $M$. Assessing Quality of life of elders with femoral neck fractures, using SF36 and EQ5D. Iranian Journal of Nursing Research. 2010;4(15):71-79.

24. Sobota A, Yamashita R, Xu Y, et al. Quality of life in thalassemia: a comparison of SF-36 results from the thalassemia longitudinal cohort to reported literature and the US norms. Am J Hematol. 2011;86(1):92-95. doi:10.1002/ajh.21896

25. Ghavamzadeh A, Nasseri P, Eshraghian MR, et al. Prognostic factors in bone marrow transplantation for beta thalassemia major: experiences from Iran. Bone Marrow Transplant. 1998;22(12):1167-1169. doi:10.1038/sj.bmt.1701509

26. Sruamsiri R, Chaiyakunapruk N, Pakakasama S, et al. Cost utility analysis of reduced intensity hematopoietic stem cell transplantation in adolescence and young adult with severe thalassemia compared to hypertransfusion and iron chelation program. BMC Health Serv Res. 2013;13:45. doi:10.1186/14726963-13-45

27. Dahlui M, Hishamshah MI, Rahman AJ, Aljunid SM. Quality of life in transfusion-dependent thalassaemia patients on desferrioxamine treatment. Singapore Med J. 2009;50(8):794799.

28. Yengil E, Acipayam C, Kokacya MH, Kurhan F, Oktay G, Ozer C. Anxiety, depression and quality of life in patients with beta thalassemia major and their caregivers. Int $\mathrm{J}$ Clin Exp Med. 2014;7(8):2165-2172.

29. Lawson SE, Roberts IA, Amrolia P, Dokal I, Szydlo R, Darbyshire PJ. Bone marrow transplantation for beta-thalassaemia major: the UK experience in two paediatric centres. $\mathrm{Br} J$ Haematol. 2003;120(2):289-295. 